\title{
Acute phase response in bovine coronavirus positive post-weaned calves with diarrhea
}

\author{
Jeong-Byoung Chae ${ }^{1,2+}$, Jinho Park ${ }^{3 \dagger}$, Suk-Han Jung ${ }^{4}$, Jin-Hee Kang ${ }^{3}$, Joon-Seok Chae ${ }^{1}$ \\ and Kyoung-Seong Choi ${ }^{5^{*}}$ (D)
}

\begin{abstract}
Bovine coronavirus (BCoV) is associated with severe diarrhea in calves, winter dysentery in adult cattle, and respiratory diseases in cattle of all ages. This study aimed to investigate the relationship between white blood cell counts and haptoglobin ( $\mathrm{Hp}$ ) and serum amyloid A (SAA) levels in post-weaned calves with diarrhea caused by BCoV and those that recovered from diarrhea. Blood and fecal samples were collected twice from the same animals; 17 postweaned calves with diarrhea (first) and 15 post-weaned calves that recovered from diarrhea (second). Real-time polymerase chain reaction revealed that all $17 \mathrm{fecal}$ samples from post-weaned calves with diarrhea and one out of 15 from diarrhea-recovered calves were positive for BCoV and negative for Cryptosporidium spp., Escherichia coli K99, Salmonella spp., bovine rotavirus, and bovine viral diarrhea virus. No Eimeria oocysts were detected using the flotation method. In comparison with post-weaned calves with diarrhea, in diarrhea-recovered calves, the lymphocyte count was significantly higher $(P=0.018)$, and the monocyte count was significantly lower $(P=0.001)$; however, the number of monocytes was still high. Post-weaned calves with diarrhea had a significantly higher Hp concentration $(P<0.001)$ compared with diarrhea-recovered calves. The results indicated that increased Hp concentration and monocytosis but not SAA may be associated with diarrhea caused by BCoV. The present study suggests that the monitoring of $\mathrm{Hp}$ concentration and monocyte count is useful in the diagnosis of post-weaned calves with diarrhea caused by BCoV in this field.
\end{abstract}

Keywords: Bovine coronavirus, Haptoglobin, Serum amyloid A

\section{Findings}

Bovine coronavirus ( $\mathrm{BCoV}$ ) is an enveloped, positivesense single-stranded RNA virus belonging to the family Coronaviridae. $\mathrm{BCoV}$ is the causative agent of severe diarrhea in calves, winter dysentery in adult cattle, and respiratory disease in cattle of all ages $[1,2]$. Infection leads to high morbidity, but usually low mortality rates. $\mathrm{BCoV}$ infection causes severe problems in cattle of various age groups, resulting in significant economic losses by affecting the weight gain or milk production. Clinical signs begin approximately 2 days after exposure and last for 3-6 days. Typically, BCoV infection in calves causes

\footnotetext{
*Correspondence: kschoi3@knu.ac.kr

${ }^{\dagger}$ Jeong-Byoung Chae and Jinho Park contributed equally to this work ${ }^{5}$ College of Ecology and Environmental Science, Kyungpook National University, Sangju 37224, Republic of Korea

Full list of author information is available at the end of the article
}

profuse watery diarrhea, and the feces can contain blood. $\mathrm{BCoV}$ replicates in the epithelial cells of colonic crypts, destroying the villi and leading to the degeneration, necrosis of the crypt epithelium, and petechial hemorrhage; this could result in severe, often hemorrhagic diarrhea in calves, which can be life-threatening due to the loss of electrolytes and malnutrition [2-4].

Acute phase proteins (APPs) are plasma proteins synthesized by e.g. hepatocytes in response to stress, infection, tissue injury or inflammation. APPs serve as the core of the innate immune response and are found in a variety of animal species [5]. Changes in the concentration of APPs have been recognized as a useful tool for assessment of cattle health. Haptoglobin $(\mathrm{Hp})$ and serum amyloid A (SAA) are most common APPs in cattle $[5,6]$. Several studies have reported changes in the concentration of APPs in several cattle diseases; 
however, few have focused on the relationship between calf diarrhea and APPs [7-9]. To date, there are no data available on the immunological changes in cattle naturally infected with $\mathrm{BCoV}$. Therefore, the objective of this study was to investigate the relationship between white blood cell (WBC) counts and APP levels in the serum of post-weaned calves with clinical signs of diarrhea caused by $\mathrm{BCoV}$ and from the same calves after recovery from diarrhea.

All procedures were performed according to the ethical guidelines for the use of animal samples, as approved by the Chonbuk National University (Institutional Animal Care and Use Committee [IACUC] Decision No. CBU 2016-00026).

At a Holstein farm located at Jiri Mountain in the Republic of Korea, sudden onset of diarrhea was observed sporadically throughout the farm by the daily farm manager. This farm raised around 200 female Holstein post-weaned calves, which were consigned from the surrounding farms. In total, 17 post-weaned calves aged 117-155 days that had diarrhea for $\geq 3$ days were randomly selected for the study. These weaned calves had no signs of respiratory disease.

Sampling was performed twice (October and December) from the same animals. First, 17 fecal samples were collected by rectal palpation on October 28 th. Ten $\mathrm{mL}$ of blood $(n=17)$ was also taken from the jugular vein and equally divided into a K2 EDTA spray-dried anti-coagulated blood collection tube (BD Vacutainer ${ }^{\circledR}$, Franklin Lakes, NJ, USA) and a SST blood tube (BD Vacutainer ${ }^{\circledR}$ ). In the laboratory, the serum was separated by centrifugation at $3000 \mathrm{~g}$ for $15 \mathrm{~min}$. After 2 months (on December 22th), all post-weaned calves with previous $\mathrm{BCoV}$ associated diarrhea were diagnosed as healthy by a local veterinarian, and blood and fecal samples $(\mathrm{n}=15)$ were taken. Samples could not be taken from two of the 17 calves, as they had already been moved to other farms. All fecal samples were stored at $-70{ }^{\circ} \mathrm{C}$ until analysis, and all serum samples were stored at $-20^{\circ} \mathrm{C}$ until use. In total, 32 blood- and 32 fecal samples were collected.

Total DNA and RNA were extracted from fecal suspensions using MagMAX ${ }^{\mathrm{TM}}$ (Thermo Fisher Scientific, Waltham, MA, USA) according to the manufacturer's instructions. Real-time polymerase chain reaction (PCR) was performed to detect Cryptosporidium spp., Escherichia coli K99, Salmonella spp., BCoV, bovine rotavirus (BoRVA), and bovine viral diarrhea virus (BVDV) using the Path-IDTM Multiplex One-Step RT-PCR Kit (Life Technologies, Carlsbad, CA, USA). All procedures were performed as previously described $[10,11]$.

Fecal samples were analyzed for the presence of oocysts using the flotation method with Sheather's solution (saturated sugar solution; specific gravity $=1.28$ ) and were examined microscopically ( $400 \times$ magnification) for Eimeria species.

Total WBC counts, including neutrophils, lymphocytes, monocytes, eosinophils, and basophils, were determined using an automatic blood analyzer (IDEXX ProCyte Dx, IDEXX Laboratories, Westbrook, ME, USA). The serum concentrations of $\mathrm{Hp}$ and SAA were measured using commercial enzyme-linked immunosorbent assay kits (Tridelta Development Ltd., Kildare, Ireland) according to the manufacturer's instructions for cattle.

All statistical analyses (normality test and Wilcoxon signed-rank test) were performed using SPSS Statistics 25 for Windows (IBM, Armonk, NY, USA). All graphical procedures were performed using GraphPad Prism 6 (GraphPad, Software, San Diego, CA, USA).

All fecal samples $(n=17)$ collected at the end of October were from post-weaned calves with diarrhea. When the second set of samples $(n=15)$ was taken in December, none of the calves displayed diarrhea. All $17 \mathrm{fecal}$ samples collected at the end of October and one fecal sample collected in December were positive for $\mathrm{BCoV}$, while Cryptosporidium spp., E. coli K99, Salmonella spp., BoRVA, BVDV or Eimeria oocysts were not detected. The mean $\mathrm{Ct}$ value for $\mathrm{BCoV}$ in fecal samples from the 17 post-weaned calves with diarrhea was 22.7 (range 18.333.2), while the Ct value of the recovered calf was 34.2. These results indicated that not only post-weaned calves with diarrhea but also one recovered calf shed $\mathrm{BCoV}$ in the feces. $\mathrm{BCoV}$ is frequently associated with hemorrhagic diarrhea in calves [12,13], however, none of the post-weaned calves in this study had hemorrhagic diarrhea. Our findings suggest that intestinal $\mathrm{BCoV}$ infection is not necessarily accompanied by hemorrhagic diarrhea in calves.

As shown in Table 1, in recovered post-weaned calves, the lymphocyte count was significantly increased $(\mathrm{P}=0.018)$, and the monocyte count was significantly decreased compared with the count of calves with diarrhea $(P=0.001)$. The leukocyte, neutrophil, lymphocyte, and eosinophil counts were within reference ranges for post-weaned calves with diarrhea and those that recovered from diarrhea, whereas the monocyte count was above the reference range in both groups (Table 1). The delta measurements (values of post-weaned calves with diarrhea minus those of recovered calves) for lymphocyte and monocyte counts were significantly different in recovered calves. The total number of WBCs has been reported to decrease with age in cattle [14]. Previous studies have shown that from 4 to 6 months of age, the mean neutrophil count gradually declined, whereas the mean lymphocyte count had an increasing trend [15]. These findings are consistent with our results. There is a lack of data of the dynamics of different blood parameters 
Table 1 White blood cell parameters in post-weaned calves with diarrhea and in those that recovered from diarrhea

\begin{tabular}{llccc}
\hline Parameters & Reference value & Diarrhea $(\boldsymbol{n}=\mathbf{1 7})$ & Recovered $(\boldsymbol{n}=15)$ & $\boldsymbol{P}$ value \\
\hline WBC $\left(10^{3} / \mu \mathrm{L}\right)$ & $4.0-12.0$ & $12.00 \pm 0.86$ & $10.17 \pm 0.67$ & 0.058 \\
NEU $\left(10^{3} / \mu \mathrm{L}\right)$ & $0.6-4.1$ & $3.31 \pm 0.72$ & $2.03 \pm 0.22$ & 0.148 \\
LYM $\left(10^{3} / \mu \mathrm{L}\right)$ & $2.5-7.5$ & $5.10 \pm 0.30$ & $6.28 \pm 0.48$ & $0.018^{*}$ \\
MON $\left(10^{3} / \mu \mathrm{L}\right)$ & $0.0-1.2$ & $3.49 \pm 0.26$ & $1.82 \pm 0.12$ & $0.001^{* *}$ \\
EOS $\left(10^{3} / \mu \mathrm{L}\right)$ & $0.0-2.4$ & $1.00 \pm 0.08$ & $0.04 \pm 0.01$ & 0.248 \\
BAS $\left(10^{3} / \mu \mathrm{L}\right)$ & $0.0-0.4$ & $0.00 \pm 0.00$ & $0.00 \pm 0.00$ & 1
\end{tabular}

Parameters are the following: white blood cells (WBC), neutrophils (NEU), lymphocytes (LYM), monocytes (MON), eosinophils (EOS), basophils (BAS)

Normal reference values were established with data obtained from Schalm's Veterinary Hematology [16]

Data are presented as the mean \pm SEM. $P$ values were obtained by Wilcoxon's rank-sum test to compare post-weaned calves with diarrhea and diarrhea-recovered calves $\left({ }^{*} P<0.05\right.$ and $\left.{ }^{* *} P<0.01\right)$

for calves at this age range; however, in the present study, all WBCs except for monocytes were within the normal reference range [16]. The reason for the increase in monocytes is unclear in the present study. Nevertheless, a previous study showed that monocytosis could occur during exposure to acute stress and in the healing phase of acute and chronic infections [14]. However, the monocyte counts vary in cattle and thus are not a reliable indicator of a specific disease [17]. Further studies are needed to explore the association between monocytes and acute phase response (APR) and to evaluate the proinflammatory cytokines in animals infected with diarrhea.

The changes in the serum $\mathrm{Hp}$ and SAA concentrations are presented in Fig. 1. Hp concentration was higher in the post-weaned calves with diarrhea $(932.0 \pm 172.0 \mathrm{mg} / \mathrm{L})$ than in the same calves recovered from diarrhea $(162.2 \pm 35.7 \mathrm{mg} / \mathrm{L})$. Hp was 5.7 fold higher in post-weaned calves with diarrhea than in those that recovered from diarrhea. There was a significant difference in $\mathrm{Hp}$ concentration $(\mathrm{P}<0.001)$ between post-weaned calves with diarrhea and recovered calves. Moreover, the concentration of SAA in post-weaned calves with diarrhea $(46.2 \pm 7.6 \mathrm{mg} / \mathrm{L})$ was higher in recovered calves $(28.5 \pm 7.4 \mathrm{mg} / \mathrm{L})$. SAA was increased 1.6-fold in post-weaned calves with diarrhea compared to the recovered calves; however, this increase was not statistically significant. The results showed that postweaned calves with diarrhea had a significant increased Hp concentration. To the best of our knowledge, this is the first study to report the relationship between $\mathrm{Hp}$ concentration and $\mathrm{BCoV}$ infection. Our findings are consistent with those of previous studies, which reported that $\mathrm{Hp}$ is a major APP in cattle $[6,18]$. SAA has been identified as an APP in various species [6]. However, compared with $\mathrm{Hp}$, changes in SAA were less pronounced in post-weaned calves with diarrhea in this

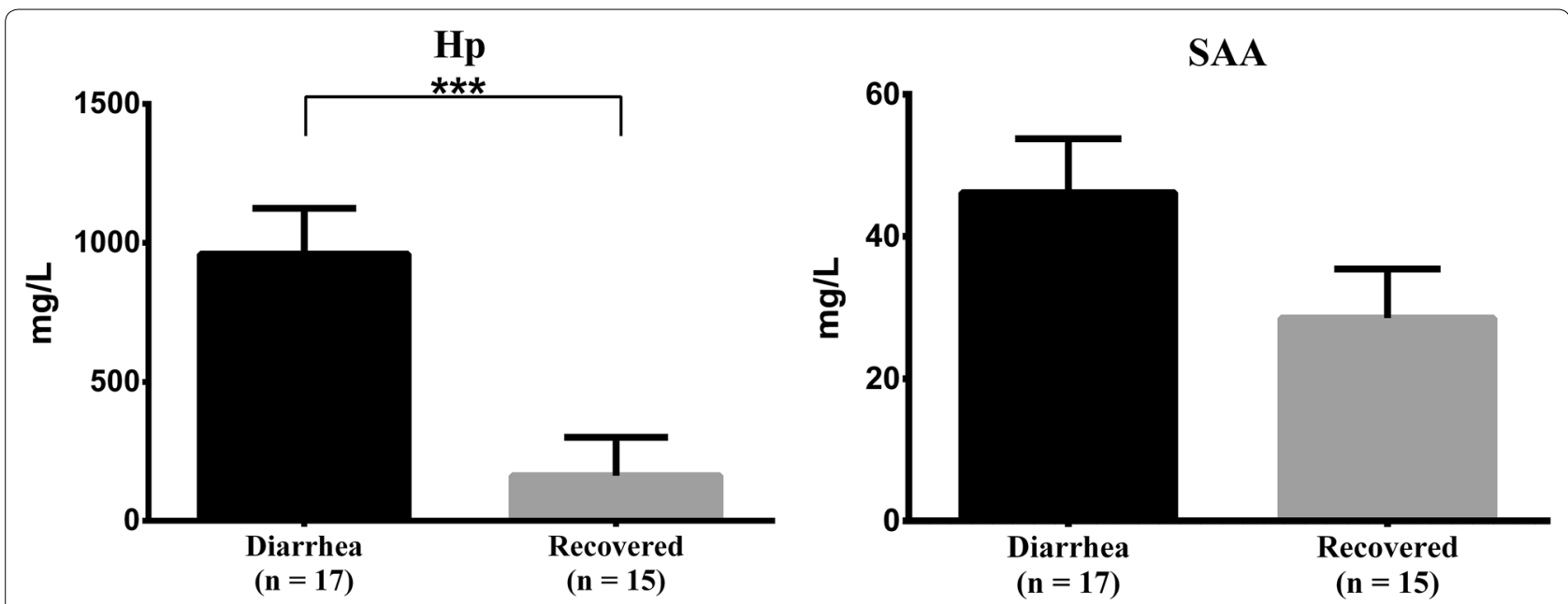

Fig. 1 Haptoglobin ( $\mathrm{Hp}$ ) and serum amyloid A (SAA) concentrations (mean $\pm \mathrm{SEM}$ ) in the serum of post-weaned calves with diarrhea ( $\mathrm{n}=17$ ) and calves that recovered from diarrhea $(n=15)$. A difference with a $P$ value less than 0.05 according to Wilcoxon's rank-sum test was considered significant $\left({ }^{*} \mathrm{P}<0.05,{ }^{* *} \mathrm{P}<0.01\right.$, and $\left.{ }^{* *} \mathrm{P}<0.001\right)$ 
study. SAA has been reported to be more sensitive to stress than disease [19-21]. Although the number of samples used was limited and a definitive conclusion could not be provided, SAA may be less suitable for the assessment of cattle health, particularly for cattle with diarrhea caused by BCoV. Normally, the concentration of APPs increases when a disease develops and decreases during recovery [22]. However, in our study, SAA neither increased significantly in post-weaned calves with diarrhea nor did it decrease significantly during recovery. Taken together, the results suggested that serum Hp concentration may be a useful diagnostic indicator to differentiate between healthy and diseased animals. Further studies are needed to evaluate the association between other APPs (fibrinogen and $\alpha_{1}$ acid glycoprotein) and diarrhea caused by $\mathrm{BCoV}$.

In conclusion, the present study is the first study that showed that post-weaned calves with diarrhea had monocytosis and a higher Hp concentration compared to recovered calves. Although we could not provide a definitive conclusion due to the limited number of samples, the increase in Hp concentration and monocyte count may be correlated with $\mathrm{BCoV}$. The results suggest that the monitoring of the $\mathrm{Hp}$ response and monocytes in addition to clinical examination and PCR may be useful for prognostic assessment at least in postweaned calves naturally affected with diarrhea caused by $\mathrm{BCoV}$.

\footnotetext{
Abbreviations

APPs: acute phase proteins; APR: acute phase response; BCoV: bovine coronavirus; BoRVA: bovine group A rotavirus; BVDV: bovine viral diarrhea virus; E. coli: Escherichia coli; EDTA: ethylenediaminetetraacetic acid; Hp: haptoglobin; SAA: serum amyloid A; real-time PCR: real-time polymerase chain reaction; WBC: white blood cell.
}

\section{Acknowledgements}

Not applicable.

\section{Authors' contributions}

JHP and KSC designed the study and drafted the manuscript. JBC, SHJ, JHK and JSC participated in sample collection. JBC, SHJ and JHK performed the experiments and performed data analysis. All authors read and approved the final manuscript.

\section{Funding}

This study was supported by the Ministry of Education of the Republic of Korea and the National Research Foundation of Korea (NRF-2017R1A2B2005685).

\section{Availability of data and materials}

The datasets used and/or analyzed during the current study are available from the corresponding author on reasonable request.

\section{Ethics approval and consent to participate}

All procedures were performed according to the ethical guidelines for the use of animal samples as approved by the Chonbuk National University (Institutional Animal Care and Use Committee [IACUC] Decision No. CBU 2016-00026).

\section{Consent for publication}

Not applicable.

\section{Competing interests}

The authors declare that they have no competing interests.

\section{Author details}

${ }^{1}$ Laboratory of Veterinary Internal Medicine, BK21 PLUS Program for Creative Veterinary Science Research, Research Institute for Veterinary Science and College of Veterinary Medicine, Seoul National University, Seoul 08826, Republic of Korea. ${ }^{2}$ Choong Ang Vaccine Laboratories Co., Ltd., CAVAC, Daejeon 34055, Republic of Korea. ${ }^{3}$ College of Veterinary Medicine, Chonbuk National University, Iksan 54596, Republic of Korea. ${ }^{4}$ National Institute of Animal Science, Rural Development Administration, Wanju 53365, Republic of Korea. ${ }^{5}$ College of Ecology and Environmental Science, Kyungpook National University, Sangju 37224, Republic of Korea.

Received: 9 March 2019 Accepted: 19 July 2019

Published online: 25 July 2019

\section{References}

1. Fulton RW, Herd HR, Sorensen NJ, Confer AW, Ritchey JW, Ridpath JF, Burge $L$. Enteric disease in postweaned beef calves associated with Bovine coronavirus clade 2. J Vet Diagn Invest. 2015;27:97-101.

2. Clark MA. Bovine coronavirus. Br Vet J. 1993;149:51-70.

3. Gunn L, Collins PJ, O'Connell MJ, O'Shea H. Phylogenetic investigation of enteric bovine coronavirus in Ireland reveals partitioning between European and global strains. Ir Vet J. 2015;68:31.

4. Boileau MJ, Kapil S. Bovine coronavirus associated syndromes. Vet Clin North Am Food Anim Pract. 2010;26:123-46.

5. Cray C, Zaias J, Altman NH. Acute phase response in animals: a review. Comp Med. 2009;59:517-26.

6. Eckersall PD, Bell R. Acute phase proteins: biomarkers of infection and inflammation in veterinary medicine. Vet J. 2010;185:23-7.

7. Deignan T, Alwan A, Kelly J, McNair J, Warren T, O'Farrelly C. Serum haptoglobin: an objective indicator of experimentally-induced Salmonella infection in calves. Res Vet Sci. 2000;69:153-8.

8. Lassen B, Bangoura B, Lepik T, Orro T. Systemic acute phase proteins response in calves experimentally infected with Eimeria zuernii. Vet Parasitol. 2015:212:140-6.

9. Seppa-Lassila L, Orro T, Lassen B, Lasonen R, Autio T, Pelkonen S, Soveri T. Intestinal pathogens, diarrhoea and acute phase proteins in naturally infected dairy calves. Comp Immunol Microbiol Infect Dis. 2015;41:10-6.

10. Cho Yl, Kim WI, Liu S, Kinyon JM, Yoon KJ. Development of a panel of multiplex real-time polymerase chain reaction assays for simultaneous detection of major agents causing calf diarrhea in feces. J Vet Diagn Invest. 2010;22:509-17.

11. Mahlum CE, Haugerud S, Shivers JL, Rossow KD, Goyal SM, Collins JE, Faaberg KS. Detection of bovine viral diarrhea virus by TaqMan reverse transcription polymerase chain reaction. J Vet Diagn Invest. 2002;14:120-5.

12. Natsuaki S, Goto K, Nakamura K, Yamada M, Ueo H, Komori T, Shirakawa H, Uchinuno Y. Fatal winter dysentery with severe anemia in an adult cow. J Vet Med Sci. 2007;69:957-60.

13. Park SJ, Kim GY, Choy HE, Hong YJ, Saif LJ, Jeong JH, Park SI, Kim HH, Kim SK, Shin SS, et al. Dual enteric and respiratory tropisms of winter dysentery bovine coronavirus in calves. Arch Virol. 2007;152:1885-900.

14. Roland $L$, Drillich M, Iwersen M. Hematology as a diagnostic tool in bovine medicine. J Vet Diagn Invest. 2014;26:592-8.

15. Khan IS, Singh C, Tejinder S, Dua K. Age related changes in blood biochemical and hematological profile of buffalo in calves. J Vet Sci Technol. 2018:9:512. https://doi.org/10.4172/2157-7579.1000512.

16. Feldman BF, Zinkl JG, Jain NC. Schalm's veterinary hematology. 5th ed Philadelphia: Lippincott Williams \& Wilkins; 2000. p. 200-4.

17. Jones ML, Allison RW. Evaluation of the ruminant complete blood cell count Vet Clin North Am Food Anim Pract. 2007:23:377-402.

18. Carter JN, Meredith GL, Montelongo M, Gill DR, Krehbiel CR, Payton ME, Confer AW. Relationship of vitamin E supplementation and antimicrobial 
treatment with acute-phase protein responses in cattle affected by naturally acquired respiratory tract disease. Am J Vet Res. 2002;63:1111-7.

19. Heegaard PM, Godson DL, Toussaint MJ, Tjornehoj K, Larsen LE, Viuff B, Ronsholt $L$. The acute phase response of haptoglobin and serum amyloid A (SAA) in cattle undergoing experimental infection with bovine respiratory syncytial virus. Vet Immunol Immunopathol. 2000;77:151-9.

20. Lomborg SR, Nielsen LR, Heegaard PM, Jacobsen S. Acute phase proteins in cattle after exposure to complex stress. Vet Res Commun. 2008;32:575-82.

21. Horadagoda NU, Knox KM, Gibbs HA, Reid SW, Horadagoda A, Edwards SE, Eckersall PD. Acute phase proteins in cattle: discrimination between acute and chronic inflammation. Vet Rec. 1999;144:437-41.
22. Nazifi S, Razavi SM, Esmailnejad Z, Gheisari H. Study on acute phase proteins (haptoglobin, serum amyloid A, fibrinogen, and ceruloplasmin) changes and their diagnostic values in bovine tropical theileriosis. Parasitol Res. 2009;105:41-6.

\section{Publisher's Note}

Springer Nature remains neutral with regard to jurisdictional claims in published maps and institutional affiliations.
Ready to submit your research? Choose BMC and benefit from:

- fast, convenient online submission

- thorough peer review by experienced researchers in your field

- rapid publication on acceptance

- support for research data, including large and complex data types

- gold Open Access which fosters wider collaboration and increased citations

- maximum visibility for your research: over $100 \mathrm{M}$ website views per year

At BMC, research is always in progress.

Learn more biomedcentral.com/submissions 